\title{
Rugosidades: desvelamentos sobre urbanização turística e patrimônio edificado
}

\author{
Sarah Marroni Minasi* \\ Universidad del Vale do Itajaí (Brasil) \\ Alcione Talaska*** \\ Instituto Federal Catarinense (Brasil) \\ Luciano Torres Tricárico**** \\ Universidad del Vale do Itajaí (Brasil)
}

\begin{abstract}
Resumo: O artigo objetiva discutir o conceito de rugosidades como condutor na análise da relação entre urbanização turística e patrimônio cultural edificado. Apresenta uma reflexão teórica, de caráter exploratório e descritivo para sistematizar o conhecimento e subsidiar uma releitura visando descrever categorias analíticas. Fundamentado em estudos anteriores identificou-se o caráter dialético na relação entre patrimônio e urbanização turística, evidenciando 2 categorias de análise: valorização e mercadoria. $\mathrm{O}$ artigo apresenta um resgate teórico dos conceitos de território usado, rugosidades e patrimônio, a fim de indicar uma leitura possível sobre processos de refuncionalização turística do território urban. A discussão contribui com categorias de análise para aplicação em novos estudos sobre sítios históricos no território urbano. Os resultados podem contribuir para novas perspectivas de planejamento e gestão do território e suas rugosidades, capaz de equilibrar as vantagens e riscos trazidos pela refuncionalização turística.
\end{abstract}

Palavras-chave: Território; Rugosidades; Patrimônio edificado; Turismo. Urbanização turística.

\section{Roughness: unveilings to tourism urbanization and built heritage}

Abstract: This paper discusses the concept of "roughness" as the driving principle in the analysis of the relationship between tourism development and built cultural heritage. It's a theoretical reflection of an exploratory and descriptive nature that aims at synthesizing existing knowledge while providing new interpretative and analytical guidelines. Working from previous studies it was possible to identify the dialectics of the relationship between cultural heritage and tourism development with perspectives centering on two classification categories, their intrinsic value and their market value. The study presents a re-think of the concepts of roughness and heritage used in urban planning aimed at re-interpreting urban space for tourism, re-appraising their possible application to heritage sites in the city. The results may open up new perspectives for urban planning and roughness and balance out the advantages and disadvantages of re-working the city space for tourism.

Keywords: Territory; Built Heritage; Tourism Development; Roughness. Tourism.

\section{Introdução}

As expressões sociais e econômicas da sociedade são materializadas territorialmente. Os modos de vida, as condições técnicas e espaciais já passadas, acumuladas historicamente, dão suporte para as características territoriais atuais. Ao mesmo tempo que, são conexões materiais e imateriais entre o passado e o presente, e pré-condições para o futuro. Essas materialidades que constituem uma referência a memória

\footnotetext{
* Universidad del Vale do Itajaí (Brasil); E-mail: sarahminasi@gmail.com; https://orcid.org/0000-0002-1193-3274

* Instituto Federal Catarinense (Brasil); E-mail: talaska.alcione@gmail.com; https://orcid.org/0000-0003-0761-3793

*** Universidad del Vale do Itajaí (Brasil); E-mail: tricarico@univali.br; https://orcid.org/0000-0003-3307-8229
} 
dos territórios, partes integrantes da conformação do espaço-tempo e foram denominadas por Milton Santos como rugosidades (Santos, 2012), em muitos casos, estas são consideradas patrimônio cultural ${ }^{1}$

Essa demarcação, enquanto patrimônio cultural, é importante ao processo de valorização do território e de suas formas-conteúdo também pelo turismo, em especial pelo segmento de turismo cultural. O desenvolvimento da atividade turística, no entanto, muitas vezes, implica na transposição do valor de uso das formas-conteúdo em valores de troca, efetivados em um processo que acontece pela refuncionalização dessas para o turismo. Tal processo é conhecido como urbanização turística (Mullins, 1991), responsável por introduzir transformações funcionais e sociais ao território a fim de promover o turismo.

Contemporaneamente, a tendência de adaptação das formas-conteúdo do território ao turismo globalizado é uma resposta à competitividade entre destinos turísticos em nível global (Cruz, 2001; Silveira \& Campos, 2012). Nesse contexto, debater a relação entre patrimônio cultural e urbanização turística, por meio do conceito miltoniano de rugosidades, significa verificar a existência de um elo entre os dois primeiros, aliando-se ao terceiro, ou seja, um ponto de equilíbrio entre os interesses da preservação das formas-conteúdo herdadas no território e os benefícios econômicos que podem ser trazidos pelo turismo. A problematização proposta está em pensar a discussão sobre rugosidades nas relações entre a mercantilização como resultado da atividade turística, repercutindo na especulação, e a apropriação do patrimônio pelos agentes locais. Uma apropriação que na maioria das vezes é resultado da fricção entre propósitos diferentes (Tsing, 2005)

No contexto da literatura científica sobre o tema, existe um conjunto de pesquisas que abordam a questão do patrimônio cultural e as rugosidades, desenvolvidas sob o ponto de vista da ciência geográfica, área de origem do termo "rugosidades" (Costa, 2008; Sabino \& Simões, 2013; Oliveira, 2016; Alves, 2017). Entre as pesquisas recentes, são destacadas temáticas que estudam a relação entre patrimônio cultural e urbanização turística, com enfoque para a refuncionalização do patrimônio edificado para uso do turismo (Sotratti, 2011; Santos, 2015; Paes, 2015) e para iniciativas de planejamento urbano e turístico via preservação do patrimônio (Pinheiro \& Santos, 2012; Assunção, 2012; Melo, 2015). De uma forma mais aprofundada, o estudo de Costa (2008), analisa a refuncionalização do patrimônio cultural pelo turismo no Brasil utilizando o conceito de rugosidades, e demonstra a viabilidade de entender e discutir, no âmbito da geografia, a questão patrimonial, o turismo e a organização do território urbano.

Costa (2008) oferece importantes subsídios para avançar na discussão, porém a interface entre rugosidades, patrimônio cultural e turismo ainda é pouco abordada nas produções científicas. Assim, surgem questões que permanecem não respondidas: Como o conceito de rugosidades, originado na Geografia, está relacionado com a urbanização e patrimônio cultural edificado? Como a área do turismo, enquanto campo de pesquisa, pode se apropriar do conceito de rugosidades para analisar e explicar as relações entre patrimônio cultural e urbanização turística?

Em virtude disso, o presente artigo possui o objetivo discutir o conceito de rugosidade como condutor na análise da relação entre urbanização turística e patrimônio cultural edificado. Para debater essa problemática, o artigo está apoiado em técnicas da pesquisa exploratória, principalmente em fontes do universo bibliográfico, analisadas sob o ponto de vista teórico, reflexivo e interpretativo, com viés qualitativo.

Deste modo, primeiramente, buscamos revisitar a concepção de território, associando a construção teórica sobre rugosidades. Para, na sequência, realizarmos uma releitura sobre a relação entre o patrimônio cultural e a refuncionalização dessas formas-conteúdo pelo turismo, considerando, igualmente, as modificações das funções do território urbano. Posteriormente, procuramos debater a relação dialética entre o patrimônio cultural e urbanização turística, à luz do conceito de rugosidades, no intuito de identificar e delinear categorias analíticas para essa relação, bem como suas características estruturantes. Longe de estabelecer uma relação maniqueísta entre os processos que atravessam o patrimônio cultural, a discussão proposta expõe os conflitos nas relações entre mercantilização e a apropriação local desse patrimônio.

\section{Território e as rugosidades}

"Território" é uma categoria de análise da geografia. O território não deixa de ser um espaço, é um espaço que relaciona aspectos físicos (recursos naturais), sociedade e poder. Pode, portanto, ser entendido como um espaço de relações que exprime manifestações (sociais, econômicas, políticas...) e está ligado a ideia de poder e de domínio.

A concepção de território possui relação direta com a compreensão de que o processo de transformação do espaço natural ${ }^{2}$, por meio da organização humana, cria uma natureza artificial, na qual o homem imprime a sua cultura, modela e humaniza o espaço denotando, assim, a sua transformação em espaço 
geográfico (Talaska, 2011). Essa transformação do espaço denota um uso de parte desse espaço natural. Uso este, compreendido não como a utilização de um "palco", no qual a sociedade se insere e o utiliza conforme suas necessidades. Mas sim, como sinônimo de "território usado" (Santos et al., 2001), que pressupõe construção do território enquanto processo histórico, material e social das ações humanas, constituindo-se de uma "trama de relações complementares e conflitantes" (Santos et al., 2001, p.02).

A concepção de território, nesse contexto, incorpora processos de apropriação do espaço pela ação social, econômica e cultural por diferentes atores da sociedade. O território é, pois, revelador, de uma realidade concreta, construída historicamente, de forma desigual, expressa na materialização dos sistemas de objetos e sistemas de ações (Santos, 2012) no espaço-tempo.

Deste modo, o que fica definido é que a apropriação e o uso do território derivam da configuração dos diferentes processos históricos. O processo de "construção do território é, pois, simultaneamente, construção / destruição / manutenção / transformação. É em síntese a unidade dialética, portanto contraditória, da espacialidade que a sociedade tem e desenvolve" (Oliveira, 2009, p.06).

\subsection{O conceito de rugosidades em Milton Santos}

Com base no conceito de território, compreendido enquanto expressão do uso, apropriação histórica e espacialidade, na qual a sociedade se desenvolve, podemos pensar em avançar para uma análise que contribua para identificar as relações entre o passado e o presente materializados sobre este espaço. Para tanto, verificamos nos escritos do geógrafo brasileiro Milton Santos, construções teóricas que possibilitam essa análise, quando alicerçadas na compreensão das chamadas "rugosidades".

$\mathrm{O}$ conceito de rugosidades (ou rugosidades espaciais) foi estudado e abordado por diferentes autores, desde o século XIX, entre eles: Karl Marx, Jean Cavaillès, Gaston Bachelard e Georges Canguilhem (Godoy, 2004). O geógrafo Milton Santos revisitou o conceito em seus estudos, objetivando fundamentar o importante papel das heranças espaciais nos diferentes períodos da história (Godoy, 2004).

Assim, Santos (2012, p. 92) definiu que as rugosidades são "a forma, espaço construído ou paisagem, o que resta do processo de supressão, acumulação e superposição com que as coisas se substituem e acumulam em todos os lugares". Concepção muito próxima de Castells (2000), que indicava as rugosidades como formas do passado, ou seja, o tempo cristalizado, ainda presente no território.

Dessa forma, mesmo de maneira isolada ou em arranjos, as rugosidades são a materialidade de ideias, de formas e de organizações sociais, econômicas e políticas pretéritas. São o registro no território da diversidade da técnica e trabalho realizado, que permite a reconstituição do seu processo formador (Sabino \& Simões, 2013).

As rugosidades presentes no território usado permitem uma aproximação entre a conformação espacial atual e a história por meio do reconhecimento de técnicas e conjunturas socioeconômicas anteriores. Produto dos legados históricos, as rugosidades são percebidas principalmente por suas formas, "são o envoltório dos instantes que marcam a evolução da sociedade" (Santos, 1982, p.42). Essas formas são a herança que permanece, ao mesmo tempo em que novas formas surgem para atender as funcionalidades do período atual. Portanto, as rugosidades são formas do passado, são a base material para memória do território, e, ao mesmo tempo, uma pré-condição para o futuro.

Santos (2012) analisa essa relação, entre passado e presente, como um reflexo da coexistência na atualidade de elementos que datam diferentes períodos históricos. Essa coexistência produz o conflito entre o antigo e o novo, impondo possibilidades e impossibilidades às ações atuais (Santos, 2012; Sabino \& Simões, 2013). A essa convivência é atribuído um caráter de resistência de padrões locais à lógica global.

As formas criadas e materializadas pelos processos sociais passados são pontos de partida, pré-condições para novas etapas (Santos, 2012). No presente, estas materialidades regularmente são adaptadas ao atendimento das necessidades atuais (Costa, 2008), existindo, muitas vezes, um processo de refuncionalização, em termos econômicos ou simbólicos, que amparam sua permanência no tempo-espaço.

Para Santos (2012), o ambiente que constitui essas materialidades, concebidas hoje como patrimônio histórico e cultural, tem papel nos eventos atuais e estão à espera para exercer funções, ainda que haja limitações quanto sua própria estrutura. Sob o impulso da modernização, as rugosidades, que antes poderiam possuir uma determinada finalidade, estão sujeitas a serem transformadas pela ação do tempo. Ou seja, as rugosidades, dessa forma, não são restritas aos elementos materiais em específico, mas também integram as memórias e imaterialidades do plano simbólico, fato que faz com que alguns autores as denominem de rugosidades patrimoniais (Oliveira, 2016)

Nesse contexto, as formas do passado existentes no território, a partir da formação histórica, são matérias-primas para a constituição de outras funções sociais, econômicas e simbólicas, como, por exemplo, 
aquelas desenvolvidas pelo turismo. A atividade turística passa a usar o patrimônio cultural, criando uma nova organização socioespacial para atendimento das demandas turísticas sob uma organização preexistente, ou seja, valorizando as rugosidades do território.

\section{Patrimônio cultural e a refuncionalização pelo turismo}

O patrimônio cultural é entendido como um testemunho das experiências vividas de uma coletividade. Além de serem uma ferramenta para conhecer o passado, possibilitam aos indivíduos estreitar os laços de pertencimento com o território. E assim, desenvolver a percepção de um conjunto de elementos comuns que funcionam como um fortalecedor do sentimento de grupo e compõem a identidade coletiva (Rodrigues, 2003).

O patrimônio enquanto referência cultural é divido em dois conjuntos, bens imateriais e materiais. O patrimônio cultural imaterial, segundo a $\operatorname{UNESCO}^{3}$ (2018), são práticas, representações, expressões, conhecimentos e técnicas - junto com instrumentos, objetos, artefatos e lugares culturais que lhe são associados - que as comunidades, os grupos e, em alguns casos, os indivíduos reconhecem como parte integrante do patrimônio cultural.

Já o patrimônio material é o conjunto composto por bens culturais tangíveis classificados segundo sua natureza: arqueológico, paisagístico e etnográfico; histórico; belas artes; e das artes aplicadas. Está dividido em bens imóveis, também conhecidos como patrimônio cultural edificado que integram os núcleos urbanos, sítios arqueológicos e paisagísticos, e bens individuais. E bens móveis, que integram as coleções arqueológicas, acervos museológicos, documentais, bibliográficos, arquivísticos, videográficos, fotográficos e cinematográficos (Santos, 2015).

O patrimônio cultural tem o papel de suporte da história e memória dos grupos sociais. É um elemento essencial na construção da identidade cultural, seja coletiva ou individual. O patrimônio cultural que até o século XX se referia somente aos bens materiais, já era assimilado como a materialização da identidade (Rocha \& Monastirsky, 2008). A importância da conservação do patrimônio surge justamente da sua contribuição à identidade de uma sociedade, grupo, comunidade, família e outros. É a herança do passado que vivenciada pelas gerações atuais serão multiplicadas às próximas gerações.

Uma comunidade atribui valor simbólico a determinados elementos da paisagem urbana, reconhecendo-os como expressão material da própria identidade (Pollice, 2010). Nesse sentido, um mesmo bem cultural recebe leituras plurais de acordo com o conteúdo simbólico que cada grupo social atribui ao patrimônio (Murta, 2008). Uma edificação pode ser reconhecida quanto ao valor histórico, qualidades estéticas ou enquanto símbolo que identifica determinado território ou região.

A sociedade constrói e reproduz a sua identidade através do contato constante com seu passado, ou seja, com os bens do patrimônio cultural. Esse contato tece um sentimento de afinidade em uma sociedade que reconhece pontos comuns entre seus indivíduos. A construção do sentimento de pertencimento acontece dentro dos contextos sociais que comungam um mesmo território, processo histórico e memória social (Rocha \& Monastirsky, 2008).

A memória social é algo exterior ao indivíduo e reserva um conteúdo histórico que deve ser acionado para compreensão dos fatos do passado tanto individual como coletivo. A própria formação do território urbano - a cidade, juntamente com o patrimônio apresentam contribuições para compreensão da arquitetura, símbolos e manifestações artístico-culturais (Assunção, 2012). O patrimônio representa o elo do indivíduo com a prática social, caracterizando-se como lugar de memória. É resultado de um processo histórico da sociedade (Rocha \& Monastirsky, 2008). Assim, é um mediador entre o tempo histórico passado, presente e futuro.

A ruptura do vínculo com o patrimônio e a memória resulta no enfraquecimento dos laços que identificam a comunidade com seu território, perdendo aos poucos os significados, os traços de reconhecimento perdem força. Como consequência o patrimônio deixa de exercer seu papel na construção da identidade cultural (Rocha \& Monastirsky, 2008; Melo, 2015; Paes, 2015). A conservação da memória e do patrimônio edificado está condicionada a inserção desses ao cotidiano das comunidades, da disposição de incorporá-los e passar para a geração seguinte. O turismo deveria desempenhar apenas um papel secundário de suporte nessa relação entre patrimônio e comunidade (Chai, 2011).

\subsection{Refuncionalização do território urbano pelo turismo}

O turismo é uma prática social que tem no território seu principal objeto de consumo, inserindo-o enquanto mercadoria no circuito de trocas. É o consumo do e no território (Qian, Feng \& Zhu, 2012). 
Entender o turismo na discussão de território, coloca a atividade como uma prática social que produz territórios com funções específicas em relação ao seu uso (Cruz, 2007).

Essa dinâmica implica na reapropriação de partes do território que ofereçam a chamada matéria-prima ao turismo, ou seja, os atrativos turísticos. No turismo cultural, é o patrimônio cultural que atende a esse pré-requisito, pelo processo de refuncionalização. Para fomentar o turismo, os patrimônios culturais são tomados como motivação para os fluxos de turistas conhecerem aspectos da cultura dos destinos turísticos (Soares, 2016). Por isso, a refuncionalização dos sítios e centros históricos pelo turismo é decorrente da adaptação do território urbano à demanda do turismo (Costa, 2008; Qian, Feng; Zhu, 2012). Integra esse processo a produção, organização e consumo do território.

No Brasil, a conservação dos sítios históricos induziu a refuncionalização pela atividade turística, visando o desenvolvimento econômico de cidades brasileiras. Esse encadeamento deve ser realizado articulando patrimônio cultural, valorização turística e planejamento (Paes, 2015). Uma vez que, a refuncionalização expressa a conversão da função dos objetos, nesse caso, os bens culturais imóveis. Essa refuncionalização é realizada por grupos sociais determinados e atende a propósitos específicos, fruto da reestruturação socioespacial urbana (Sotratti, 2011; Qian, Feng \& Zhu, 2012).

Os bens edificados que resistem à transformação do território urbano passam a incorporar novas funções a medida em que ações são dirigidas estrategicamente por meio do planejamento urbano. O patrimônio cultural é refuncionalizado para atender funções vinculadas ao turismo, cultura, comércio, entre outros (Sotratti, 2011).

O tempo e as paisagens urbanas, os elementos da sociedade são transformados em bens de consumo para o turismo (Law, 2000; Luchiari, 2004; Santos, 2010). O consumo do território acontece com o deslocamento do valor de uso para o valor de troca (Carlos, 2002). No âmbito do patrimônio, também resulta na transformação do valor cultural em valor de troca. O patrimônio cultural é incorporado como atrativo turístico para mercantilização do território (Mitchel, 2000; Costa, 2008;).

A cidade como local do trabalho, residência e lazer passa a ser vista além disso, como objeto de consumo e campo da experiência turística (Soares, 2016). O território reapropriado pelo turismo também é local da vida cotidiana. Por isso o processo de refuncionalização é permeado de contradições entre uso turístico e os demais usos já existentes, dado que nos sítios históricos acontecem transformações funcionais e sociais (Ashworth \& Page, 2011; Chai, 2011; Pinheiro \& Santos, 2012).

O fomento do turismo em determinado território exige a implementação de infraestrutura de apoio $^{4}$ e turística para subsidiar seu desenvolvimento (Cao et al., 2013). Já a urbanização turística é responsável pelo adensamento especificamente da infraestrutura turística e tem como característica atender exclusivamente as necessidades do turista (Mullins, 1991; Luchiari, 2004).

Em uma sociedade globalizada, a demanda também é globalizada e a adequação dos lugares segue a racionalidade da competitividade global entre os produtos e destinos turísticos (Sánchez, 2010; Pinheiro \& Santos, 2012). Nesse contexto é possível fazer um paralelo com o conceito de fricção de Tsing (2005). Segundo a autora, a friç̧ão evidencia a conectividade entre opostos, seja por interesses ou até no nível global x local.

Ocorre a busca pela idealização do turismo globalizado (Berdoulay, 2009;), mesmo que esses destinos sejam escolhidos por suas particularidades (Pecqueur, 2006) e a fricção é um processo que pode fazer frente à globalização perversa (Santos, 2000; Tsing, 2005). Assim, as novas funções alimentadas pelo turismo promovem a transformação e revalorização dos objetos em relação ao passado. As mudanças funcionais e simbólicas nos usos do patrimônio e a urbanização turística destacam os contrastes entre espaços para turistas e comunidade (Mitchel, 2000; Paes, 2015; Santos, 2015).

Nascem territórios com concentração de infraestrutura turística e paisagens de alto valor simbólico projetados ao mercado global (Sotratti, 2011). Enquanto, de outro lado está o território como materialidade da realização da vida humana que tem no patrimônio cultural a evidência física da memória da cidade (Carlos,2002; Santos, 2010).

\section{Discussão}

\subsection{Relação dialética entre patrimônio cultural e turismo}

A partir da leitura e análise dos estudos de casos (Chai, 2011; Pinheiro \& Santos, 2012; Santos, 2015; Paes, 2015; Amin \& Adu-Ampong, 2016; Mkadem et al., 2017; Sjöholm, 2017; Silva, 2018; Albuquerque \& Tavares, 2019) com base nas referências de Milton Santos sobre rugosidades foi delineada uma discussão crítica. Os resultados dos casos mostram que a relação patrimônio cultural e turismo são atravessadas por uma dialética. 
O contexto da globalização na atualidade permeia a relação entre patrimônio cultural e turismo, destacando aqui o processo de urbanização turística. Uma relação que não é necessariamente de partes antagônicas, mas que assumem esse caráter pela presença de forças externas no território urbano impulsionadas pela globalização. Nessa relação estão os interesses na conservação dos bens culturais e os benefícios econômicos atribuídos ao desenvolvimento do turismo (Melo, 2015).

As cidades concentram os bens culturais (rugosidades) e precisam contemplar o patrimônio edificado dentro dos eixos de desenvolvimento. Diante disso encontram na atividade turística, por meio do segmento de turismo cultural, uma alternativa para garantir os custos de manutenção dos sítios históricos (Chai, 2011; Melo, 2015). Dessa forma, é desenhada uma relação dialética que coloca a refuncionalização com o propósito de conservação do patrimônio que pode resultar tanto na padronização do bem para satisfazer o consumo de massa ou na valorização pela apropriação do bem pela comunidade local. Ao mesmo tempo em que o turismo pode gerar os recursos fundamentais para conservação dos bens culturais, pode prejudicar os lugares e práticas culturais ligadas a eles (Murta, 2002; Chai, 2011) (Figura 1).

\section{Figura 1: Relação dialética entre patrimônio cultural e urbanização turística no conceito de rugosidades.}

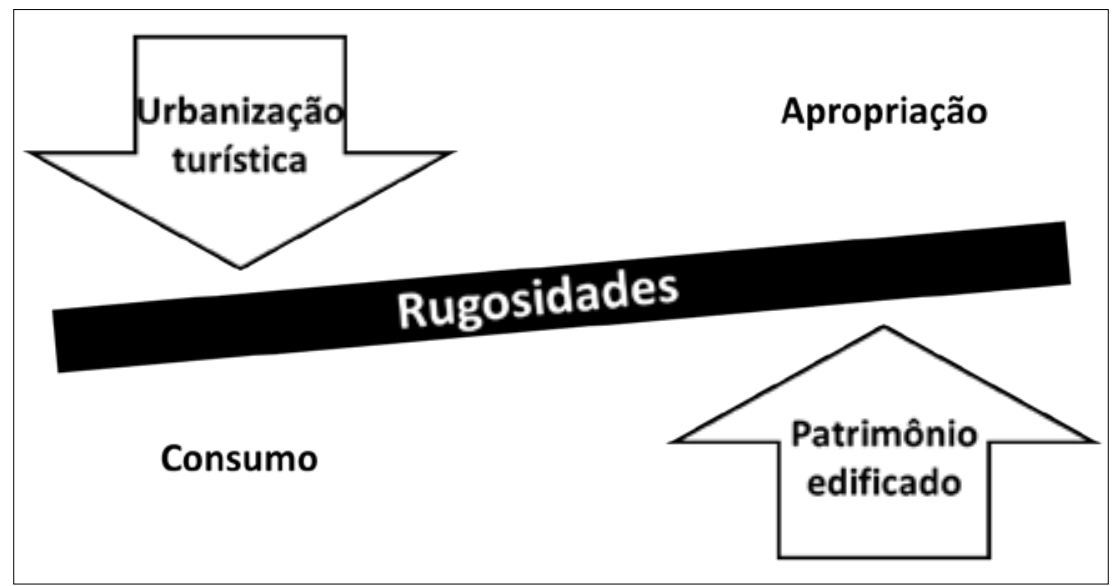

Fonte: elaborado pelos autores, 2019.

Quando o turismo se desenvolve de acordo com forças exógenas à comunidade pode resultar no uso indevido do patrimônio, sob o ponto de vista da comunidade local/regional. A forma deliberada da atividade turística transforma manifestações culturais em "cenarização" e "espetacularização". Estas, são forças responsáveis pela criação de ambientes artificiais e simulacros nos destinos turísticos. Assim, surgem cenários nos quais é observada a padronização de produtos, a fragmentação das identidades e homogeneização das culturas. Mas, é um processo que atende a reprodução da lógica do turista (Santos, 2015).

Por outro lado, os fluxos de turistas direcionados aos sítios históricos incrementam o valor simbólico atribuído a esses locais (Pinheiro \& Santos, 2012). Mesmo que os territórios reapropriados pelo turismo sejam aqueles com alto valor simbólico, por vezes, estes ficam esquecidos nos processos de planejamento urbano. A presença do turismo, nesse contexto, transforma o que antes era marginalizado em objeto dos esforços da reestruturação urbana e econômica (Sotratti, 2011). Um movimento cada vez mais presente por meio de estratégias de refuncionalização pela urbanização turística.

O turismo cultural está, assim, sustentado na partilha dos bens patrimoniais entre turistas e comunidades locais. Esse compartilhamento visa a conservação do bem patrimonial, ao mesmo tempo, que tem como objetivo criar entretenimento ao turista e servir de referência à memória da cidade (Chai, 2011) . Ambos, turismo e patrimônio, estão alicerçados em uma base material e imaterial. Característica intrínseca às rugosidades, que de acordo com Santos (2012) não podem ser apenas encaradas como heranças fisicoterritoriais, mas também como heranças socioterritoriais. 


\subsection{Categorias de análise das rugosidades e a relação entre patrimônio cultural e urbanização turística}

Com base no conceito de rugosidades, explicitado por Milton Santos (Santos, 1986; Santos, 2012) e identificado nas pesquisas de Chai (2011), Pinheiro e Santos (2012), Melo (2015), Santos (2015), Paes (2015), Amin e Adu-Ampong (2016), Mkadem et al., (2017), Sjöholm (2017), e Albuquerque e Tavares (2019) foi possível identificarmos categorias de análise para o aprofundamento do pensamento crítico sobre patrimônio e urbanização turística a partir da relação dialética. Nesse contexto, para fundamentar a discussão foram especificadas duas categorias analíticas: valorização e mercadoria.

A primeira categoria, valorização, remete à questão do patrimônio como suporte da memória da cidade. O patrimônio percebido por seu valor simbólico pela comunidade territorialmente localizada. Já a segunda categoria, mercadoria, faz referência à superação do valor enquanto conjunto histórico e simbólico, pelo valor econômico e mercantil do bem patrimonial refuncionalizado pela urbanização turística.

$\mathrm{Na}$ categoria valorização é essencial entender para além dos aspectos físicos, que as rugosidades interconectam o território pelas relações com o passado. A valorização do patrimônio e a utilização para o turismo são formas de valorizar o passado do território urbano na atualidade. As rugosidades constantemente sofrem pressão dos movimentos de expansão urbana, encontrá-las no território demonstra o engajamento para sua conservação. Nessa situação, os patrimônios edificados assumem valiosa força simbólica, sendo indicativo de que existe um relacionamento entre a sociedade e sua memória. Uma vez escolhidas por determinados grupos sociais, essas rugosidades tornam-se representações materiais e imateriais de tempos, espaços e acontecimentos específicos.

O engajamento da comunidade com as autoridades públicas locais para a conservação do patrimônio edificado em Georgetown, por exemplo, levou Chai (2011) a concluir que um patrimônio sem alma, isto é, sem apropriação e reconhecimento pela comunidade, não desenvolverá um turismo cultural sustentável. Mkadem et al., (2018) trazem o caso da Medina de Chefchaouen no Marrocos, em que partiu da comunidade local a iniciativa para valorizar o patrimônio cultural. De acordo com os autores, existe um interesse em preservar os bens patrimoniais pelo respeito e afeto ao local sem que isso implique em conferir valor econômico.

Assim, independente das ações realizadas pelos órgãos de proteção ao patrimônio, é a apropriação pela relação de referência à memória do território urbano que o legitima como patrimônio cultural (Oliveira, 2015). E as rugosidades abrem a possibilidade de redescoberta das formas do passado associadas à história da própria comunidade que a produziu. A retomada do patrimônio pela comunidade, como destacado pelo Melo (2015), não trata apenas de benefícios econômicos, é a valorização das rugosidades que reforça a questão identitária.

O exemplo do Centro Histórico de Aracajú (SE) ilustra essa questão, pois os projetos de restauração e refuncionalização do patrimônio edificado foram realizados objetivando a modalidade de turismo associado à reapropriação das rugosidades pela comunidade. Houve, portanto, o incentivo ao fortalecimento de atividades comerciais tradicionais no local e resgate da relação histórica entre o território urbano central e o rio Sergipe (Pinheiro \& Santos, 2012).

O valor do patrimônio não deve ser resumido ao uso turístico. Esse valor também deve considerar o sentimento de pertencimento a uma cultura e história compartilhada por seus habitantes (Pinheiro $\&$ Santos, 2012). Aliado a isso, o turismo passa a conferir vantagens comparativas diferenciando os destinos turísticos pela particularidade e não pela padronização (Pecqueur,2006). Dessa forma, o patrimônio edificado deve atender primeiramente às práticas culturais representativas da identidade cultural da comunidade, e não à lógica do consumo do patrimônio como mercadoria (Law, 2000; Luchiari, 2005; Costa, 2008). Portanto, a categoria mercadoria carrega um conteúdo divergente do conteúdo da categoria valorização.

Se por um lado é perceptível a crescente valorização do patrimônio cultural pelo turismo, por outro lado, a refuncionalização intensifica a produção de lugares para o consumo (Melo, 2015), configurando assim a categoria de análise mercadoria. A adaptação à atividade turística pode resultar em um cenário reconhecido principalmente pelo valor estético (Ateljevic, Pritchard \& Morgan, 2007). Mesmo sob o pretexto de salvaguardar a memória coletiva, os lugares turísticos concentram funções de hospedagem, alimentação e entretenimento trazidas pela urbanização turística (Sotratti, 2011). Logo, visam atender a demanda do turismo.

No sítio histórico de Paraty (RJ), por exemplo, essa característica é evidenciada pela autora Paes (2015), onde o acesso ao consumo cultural não é democraticamente distribuído. Embora o centro da cidade seja um espaço público, dividido entre moradia, comércio e edificações mistas, este não é um 
local acessível à maior parte da população devido aos altos preços agregados às mercadorias e serviços com a chegada do turismo (Paes, 2015). A partir de entrevistas com moradores, Paes (2015) concluiu que houve o afastamento dos moradores locais em relação ao centro histórico de Paraty ${ }^{5}$.

A refuncionalização turística dos patrimônios edificados pode interferir nas representações simbólicas ligadas ao valor histórico (Sotratti, 2011; Korstanje \& Seraphin, 2017). E o resultado são ambientes economicamente profícuos ao turismo, no entanto desconectados do contexto em que se inserem (Mitchel, 2000; Murta, 2008). As ações de refuncionalização dos sítios históricos direcionadas apenas aos benefícios econômicos do turismo realçam o caráter dialético entre patrimônio e mercadoria (Sabino \& Simões, 2013; Korstanje \& Seraphin, 2017).

Situação presente também no caso de São Luiz do Paraitinga (SP), Brasil, onde o aumento no volume do fluxo de turistas que demandam o consumo de bens culturais despertou o interesse do poder público para o turismo (Santos, 2015). O paradigma do consumo foi favorecido em detrimento ao incentivo do patrimônio como base material de referência à memória coletiva e identidade local (Ateljevic, Pritchard \& Morgan, 2007). O mesmo foi apresentado por Albuquerque e Tavares (2019) sobre a Avenida Nazaré em Belém (PA), Brasil. Nesse caso, os resultados da pesquisa demonstram que o capital imobiliário usa o patrimônio, dentro da relação de negócio, de duas formas. A primeira pela apropriação física e simbólica do patrimônio, para atrair os consumidores. A segunda forma refere-se à apropriação do bem patrimonial nos discursos de vendas e marketing (Albuquerque \& Tavares, 2019).

$\mathrm{Na}$ cidade histórica de Sulaimaniyah no Iraque embora exista uma visão compartilhada da necessidade de preservar o patrimônio cultural, o processo de gestão é conflituoso (Amin \& Adu-Ampong, 2016). A situação é agravada pelos recursos financeiros limitados disponíveis e as significativas diferenças de poder entre as partes interessadas no processo de tomada de decisão, apontam Amin e Adu-Ampong (2016), o que geralmente significa que os residentes estão excluídos e os interesses privados se sobrepõem aos interesses de preservação. Da mesma forma, Sjöholm (2017) destaca que em Kiruna, Suécia as decisões sobre o planejamento envolvendo o patrimônio edificado favoreceram os interesses da empresa de mineração, responsável pela mineração de ferro na cidade, sobre o significado cultural dos bens para a cidade.

Em São Luiz do Paraitinga e Kiruna as transformações ocorreram nas materialidades, sobretudo localizadas no centro histórico do território urbano. Uma consequência de ações direcionadas unicamente ao atendimento das necessidades dos turistas (Santos, 2015). O mesmo foi evidenciado em Paraty (RJ),

Figura 2: Categorias de análise das rugosidades e suas características

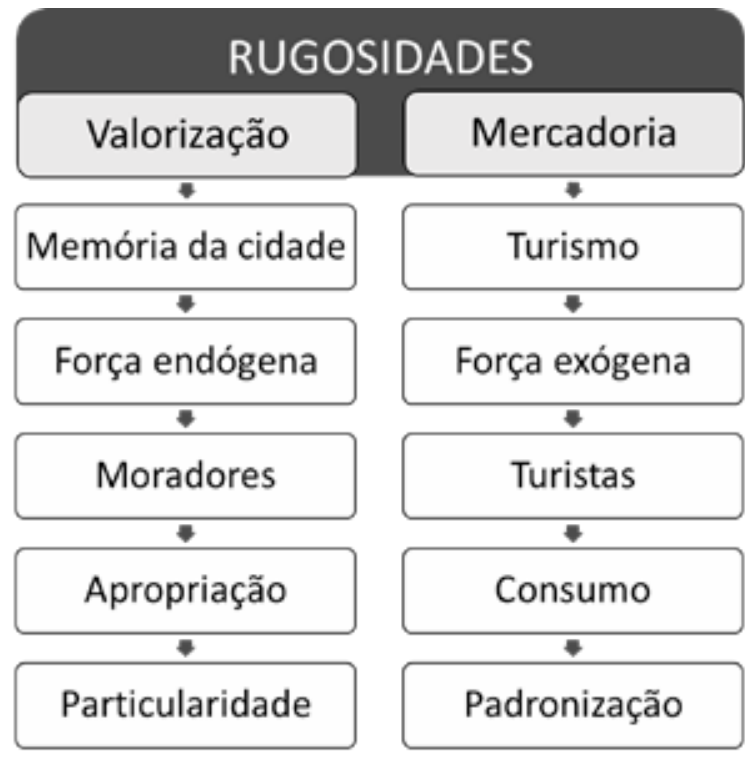

Fonte: elaborado pelos autores, 2019. 
com a instalação de infraestrutura e serviços turísticos no centro histórico, no qual a pressão do uso turístico acabou descaracterizando o conjunto original tombado ao passo que foi permitida a construção de edificações em "estilo patrimônio", produzindo um simulacro no conjunto arquitetônico (Paes, 2015).

Os exemplos questionam criticamente o processo de refuncionalização das rugosidades pela urbanização turística do patrimônio edificado. O progressivo uso turístico do patrimônio é reconhecido como tendência. Contudo, é preciso pensá-lo por meio do equilíbrio dos interesses dos agentes sociais, especialmente a comunidade local (Melo, 2015; Mkadem et al., 2017). Desenvolver o turismo como atividade capaz de ressaltar o valor simbólico do patrimônio, invés de apresentar o passado como um parque temático (Silberman, 2007). As categorias apresentam características que se contrapõem, demonstrando o caráter dialético da discussão entre patrimônio e urbanização turística à luz do conceito de rugosidades (Figura 2).

Nos casos apresentados de refuncionalização das rugosidades pela atividade turística, quando consideramos a categoria analítica "valorização", verificamos a predominância da apropriação e conservação, enquanto prática da cidadania para referência da memória do território urbano. Com isso, mesmo que algumas materialidades atendam a reprodução do capital, outras resistem como formas do passado e espaços para a comunidade local/regional.

Na categoria analítica "mercadoria", as rugosidades, mesmo quando associadas à história, cultura e identidade dos lugares, são refuncionalizadas segundo os interesses do mercado e da demanda global em contraposição à comunidade local/regional, como ponto de friç̧ão pela prática do poder econômico (Tsing, 2005). Fato que ocasiona um movimento em que as formas-conteúdo do passado perdem seus significados como referência física da memória do território urbano, sendo ultrapassados pelo o que representam como infraestrutura turística (Sotratti, 2011). A relação entre turismo e patrimônio cultural, dessa forma, é permeada pelo processo de estetização das formas e funções exclusivamente para o consumo (Silberman, 2007).

\section{Considerações finais}

Com base no objetivo central esse artigo contribui para a ampliação da discussão do conceito de rugosidades, ressaltando-o como condutor na análise da relação entre urbanização turística e patrimônio cultural edificado. O conceito de rugosidades está relacionado com a urbanização turística e o patrimônio cultural edificado pela indicação do caráter dialético, portanto contraditório, desse vínculo.

Ao pensar em como a área do turismo, enquanto campo de pesquisa, pode se apropriar do conceito de rugosidades para analisar e explicar as relações entre patrimônio cultural e urbanização turística, foram delineadas duas categorias de análise da relação entre urbanização turística e patrimônio: valorização e mercadoria. Essas categorias evidenciam uma via de mão dupla. A urbanização turística ao acrescentar infraestrutura turística aos sítios históricos, refuncionalizando os bens patrimoniais, pode colaborar com os esforços de conservação do patrimônio edificado, e pode privilegiar os benefícios econômicos para consumo global.

Portanto, apontamos como aporte teórico a indicação das categorias analíticas das rugosidades no contexto do patrimônio cultural e da urbanização turística que contribuem para identificar a situação dos bens patrimoniais. Com base nessas categorias sua aplicabilidade prática é revertida em subsídios para a gestão do patrimônio e do turismo e colabora para estabelecer o equilíbrio entre apropriação e consumo.

Diagnósticos de pesquisas empíricas baseadas nas categorias mercadoria e valorização podem redirecionar o futuro das formas-conteúdo. Ao dispor dessas informações é possível formular políticas públicas para evitar o desgaste provocado pela mercantilização e ausência de medidas de conservação e restauro. Pode elevar o futuro da discussão do tema incorporando estratégias mais inovadoras e sustentáveis no campo do patrimônio edificado.

A discussão desse estudo apresenta limitações por ser uma pesquisa apoiada em casos já analisados, portanto uma análise teórica. Em pesquisas futuras seria conveniente optar pela aplicação prática das categorias em estudos de casos múltiplos como forma de validação empírica das categorias. Cabe investigar também como a cidadania pode desenvolver vínculos simbólicos com as rugosidades patrimoniais independentemente do turismo.

Por fim, ressaltamos, com base em pesquisas anteriores, que existe uma aproximação entre os conceitos de patrimônio cultural e urbanização turística capaz de ser compreendida através das categorias de análise mercadoria e valorização. Resgatamos o papel de reflexão teórica deste artigo propondo um diálogo conduzido pelo conceito de rugosidades, entre os constructos patrimônio cultural e urbanização 
turística. O esforço teórico desse artigo explicita a relação dialética entre patrimônio e turismo, com suas diferentes nuances, relacionando-o com o processo de formação histórica das organizações socioespaciais.

\section{Agradecimentos}

O presente trabalho foi realizado com apoio da Coordenação de Aperfeiçoamento de Pessoal de Nível Superior - Brasil (CAPES) - Código de Financiamento 001.

\section{Bibliografía}

Albuquerque, V. L. M., \& Tavares, M. G. 2019. O patrimônio usado como negócio na Avenida Nazaré em Belém-PA. Papers do NAEA, 28(3), p.260-283.

Alves, M. C. 2017. "Usos do território e rugosidades: fundamentos socioespaciais do patrimônio histórico do estado do Ceará", Tese de Doutorado, Faculdade de Filosofia, Letras e Ciências Humanas, Universidade de São Paulo, São Paulo, disponível em: https://bit.ly/2XNJW7Q (acessado em 7 março 2019)

Amin, H. M. T. M., \& Adu-Ampong, E. A. 2016. Challenges to urban cultural heritage conservation and management in the historic centre of Sulaimaniyah, Kurdistan-Iraq. Journal of Cultural Heritage Management and Sustainable Development, 6(3), p.255-270.

Ashworth, G. \& Page, S. J. 2011. "Urban tourism research: Recent progress and current paradoxes", Tourism management, Vol. 32 No. 1, pp. 1-15, disponível em https://doi.org/10.1016/j.tourman.2010.02.002 (acessado em 7 março 2019)

Assunção, P. 2012. "Turismo e processo de urbanização: desafios na preservação do patrimônio natural e cultural", Revista Acadêmica Observatório de Inovação do Turismo, Vol. 7 No. 2, pp.17-32, disponível em: http://dx.doi.org/10.12660/oit.v7n2.6888 (acessado em 7 março 2019)

Ateljevic, I.; Pritchard, A.; Morgan, N. 2007. The critical turn in tourism studies: innovative research methodologies, Routlege, Amsterdan.

Berdoulay, V. 2009. "La Historia de la Geografía en el Desafío de la Prospectiva" Boletín de la A.G.E, No. 51, pp. 09-23, disponível em: https://bit.ly/2u5KLLD (acessado em 7 março 2019)

Cao, N., Ma, Y., LI, T. \& Bai, K. (2013), "Study on the Coordinative Development between Tourism Industry and Urbanization Based on Coupling Model: A Case Study of Xi'an”, Tourism Tribune, Vol. 28 No. 1 , pp. $62-68$.

Carlos, A. F. 2002. "A geografia brasileira, hoje: algumas reflexões", Terra Livre, Vol. 1 No. 18, pp.161-178, disponível em: https://bit.ly/2ELKSka (acessado em 7 março 2019)

Castells, M. 2000. A sociedade em rede, Editora Paz e Terra, Rio de Janeiro, RJ.

Chai, L. T. 2011. "Culture heritage tourism engineering at Penang: Complete the puzzle of 'the pearl of orient”, Systems Engineering Procedia, Vol. 1, pp. 358-364, disponível em: https://doi.org/10.1016/j. sepro.2011.08.054 (acessado em 7 março 2019)

Costa, E. B. 2008. "Refuncionalização de patrimônio cultural e a nova racionalidade da organização socioespacial em núcleos urbanos tombados", Estudos Geográficos, Vol. 6 No. 2, pp.53-73, disponível em: https://bit.ly/2H8mYmy (acessado em 7 março 2019)

Cruz, R.C. 2001. Política de Turismo e Território, Contexto, São Paulo, SP.

Cruz, R.C. 2007. Geografias do turismo: de lugares a pseudo-lugares, Roca, São Paulo, SP.

Godoy, P. R. T. 2004. "Uma reflexão sobre a produção do espaço", Estudos Geográficos: Revista Eletrônica de Geografia, Vol. 2 No. 1, pp. 29-42.

Korstanje, M. \& Séraphin, H. 2017. "Revisiting the sociology of consumption in tourism", in Dixit, S. (Ed.), The Routledge Handbook of Consumer Behaviour in Hospitality and Touris, Routledge, New York, NY, pp. 46-55.

Law, C. M. 2000. Urban Tourism: Attracting Visitors do Large Cities, Biddles Ltd, London.

Luchiari, M. T. D. P. 2004. "Urbanização turística: um Novo Nexo entre o Lugar e o Mundo", in Serrano, C., Bruhns, H. T. \& Luchiari, M. T. D. P. (Ed.), Olhares Contemporâneos sobre o Turismo. Papirus, Campinas, SP, pp.105-130.

Luchiari, M. T. D. P. 2005. "A reinvenção do patrimônio arquitetônico no consumo das cidades", GEOUSP - Espaço e Tempo, No. 17, pp.95-105, disponível em: https://bit.ly/2JahlWG (acessado em 7 março 2019)

Melo, M. A. W. S. 2015. "Turismo e patrimônio cultural: processo de tombamento e estratégias de utilização turística do Centro Histórico de Natal/RN", master thesis, Centro de Ciências Sociais Aplicadas, 
Universidade Federal do Rio Grande do Norte, Natal, disponível em: https://bit.ly/2EMUACT (acessado em 7 março 2019)

Mitchell, D. 2000. Cultural Geography: A Critical Introduction, Blackwell, Oxford.

Mkadem, A. B., Zakriti, A., \& Nieuwenhuysen, P. 2018. Pay or preserve: a new approach to valuing cultural heritage. Journal of Cultural Heritage Management and Sustainable Development, 8(1), p.2-16. DOI:10.1108/jchmsd-11-2014-0040

Mullins, P. 1991. "Tourism urbanization", International journal of urban and regional research, Vol. 15 No. 3, pp. 326-342, DOI: 10.1111/j.1468-2427.1991.tb00642.x

Murta, R. S. 2008. "A transformação do espaço urbano em função do turismo", in V Seminário da Associação Nacional de Pesquisa e Pós-Graduação em Turismo proceedings in Belo Horizonte, Brasil, 2008, ANPTUR, São Paulo, pp.1-13.

Murta, S. M. 2002. "Turismo histórico-cultural: parque temáticos, roteiros e atrações âncora", in Murta, S. M. \& Albano, C. (Ed.), Interpretar o patrimônio: um exercício do olhar, UFMG, Belo Horizonte, MG, disponível em: https://bit.ly/2TC1Pa9 (acessado em 7 março 2019)

Oliveira, A. U. 2009. "Os Agrocombustíveis e a produção de alimentos", in XII Encontro de Geógrafos da América Latina (EGAL) proceedings in Montevideo, Uruguai, 2009, EGAL, pp.1-15, disponível em: https://bit.ly/2MKG7Kj (acessado em 7 março 2019)

Oliveira, R. F. 2015. "Contribuição do conceito de rugosidade espacial para o entendimento provisório dos conteúdos urbanos e o potencial escancaramento das contradições sociais na metrópole", in XV Encontro de Geógrafos da América Latina proceedings in Havana, Cuba, 2015, ICAIC, Havana, pp. 1-15, disponível em: https://bit.ly/2SS1ufd (acessado em 7 março 2019)

Oliveira, R. F. 2016. "Rugosidades: conceito geográfico para pensar o patrimônio cultural", in XVIII Encontro Nacional de Geógrafos proceedings in São Luís do Maranhão, Brasil, 2016, Instituto Nacional de Pesquisas Espaciais, São Paulo, SP, pp.1-11.

Paes, M. T. D. 2015. "Trajetórias do patrimônio cultural e os sentidos dos seus usos em Paraty, RJ", Resgate: Revista Interdisciplinar de Cultura, Vol. 23 No.30, pp.105-118.

Pecqueur, B. 2006. "Le tournant territorial de l'économie globale", Espaces et sociétés, Vol. 124-125 No. 1, pp. 17-32, disponível em: https://doi.org/10.3917/esp.124.0017 (acessado em 7 março 2019)

Pinheiro, R. C. S. \& Santos, C. A. J. 2012. "Revitalização urbana e turismo: o caso do Centro Histórico de Aracaju (Sergipe, Brasil)", Turismo e Sociedade, Vol. 5 No. 1, pp. 275-294, disponível em: http:// dx.doi.org/10.5380/tes.v5i1.25500 (acessado em 7 março 2019)

Pollice, F. 2010. "O papel da identidade nos processos de desenvolvimento local", Espaço e Cultura, No. 27, pp. 7-23, disponível em: https://bit.ly/2HjAink (acessado em 7 março 2019).

Qian, J., Feng, D. \& Zhu, H. 2012. "Tourism-driven urbanization in China's small-town development: A case study of Zhapo Town, 1986-2003”, Habitat International, Vol. 36 No. 1, pp. 152-160, disponível em: https://doi.org/10.1016/j.habitatint.2011.06.012 (acessado em 7 março 2019).

Rocha, A. R. P. \& Monastirsky, L. B. 2008. "A dialética entre o global e o local: um olhar sobre o turismo e o patrimônio cultural”, Terr@Plural, Vol. 2 No. 1, pp. 145-154, disponível em: http://dx.doi.org/10.5212/ TerraPlural.v.2i1.145154 (acessado em 7 março 2019)

Rodriques, M. 2003. "Preservar e consumir: o patrimônio histórico e o turismo", in Funari, P.P. \& Pinsky, J.(Ed.), Turismo e patrimônio cultural. Contexto, São Paulo, SP, pp.13-24.

Sabino, A. \& Simões, R. 2013. "Geografia e Arqueologia: uma visão do conceito de rugosidades de Milton Santos”, Revista de Arqueología Pública: Revista eletrônica do Laboratório de Arqueologia Pública de Unicamp, Vol. 7 No. 2[8], pp. 174-188, DOI: 10.20396/rap.v7i2.8635705.

Sánchez, F. 2010. A reinvenção das cidades para um mercado mundial, Argos, Chapecó, SC.

Santos, C. M. P. 2015. "A patrimonialização de São Luiz do Paraitinga: a refuncionalização turística e a preservação do patrimônio cultural”, Revista Cenário, Vol. 3 No. 4, pp. 63-82.

Santos, M. 1982. Espaço e sociedade, Vozes, Petrópolis, RJ.

Santos, M. 1986. O trabalho do geógrafo no terceiro mundo, Hucitec, São Paulo, SP.

Santos, M. (2000). Por uma outra globalização: do pensamento único à consciência universal. São Paulo: Record.

Santos, M. 2012. A Natureza do Espaço: Técnica e Tempo, Razão e Emoção, USP, São Paulo, SP.

Santos, M. et al. 2001. "O papel ativo da Geografia: um manifesto", Biblio 3W. Revista Bibliográfica de Geografia y Ciencias Sociales, No. 270, disponível em: http://www.ub.edu/geocrit/b3w-270.htm (acessado em 7 março 2019) 
Santos, T. B. B. 2010. "Contradições do turismo na sociedade de consumo", in Pelegrini, S., Nagabe, F. \& Pinheiro, A. P. (Ed.), Turismo e Patrimônio em tempos de globalização, Felcicam, Campo Mourão, PR, pp.161-190.

Silberman, N. 2007. "Sustainable Heritage? Public Archaeological Interpretation and the Marketed Past", in HAMILAKIS, Yannis; DUKE, Philip (Ed.), Archaeology and capitalism: from ethics to politics, Left Coast Press, Amherst, Massachusetts, pp. 179-193.

Silveira, R. L. L. \& Campo, H. A. 2012. "Processos participativos em experiências recentes de planejamento regional: o caso do Vale do Rio Pardo (RS)", REDES, Vol. 17 No. 1, pp. 203 - 216, disponível em: http://dx.doi.org/10.17058/redes.v17i1.2687 (acessado em 7 março 2019)

Sjöholm, J. 2017. Authenticity and relocation of built heritage: the urban transformation of Kiruna, Sweden. Journal of Cultural Heritage Management and Sustainable Development, 7(2), p. 110-128. DOI:10.1108/jchmsd-11-2015-0041

Soares, C. Q. D. 2016. "Cidades e turismo cultural: algumas considerações", Revista do Instituto Histórico e Geográfico do Rio Grande do Sul, No.151, pp.251-263, disponível em: https://bit.ly/2EEW028 (acessado em 7 março 2019)

Sotratti, M. A. 2011. "A produção turística das cidades atuais: imagens e representações simbólicas de espaços e lugares”, Geo UERJ, Vol. 2 No. 22, pp. 250-271, disponível em: https://doi.org/10.12957/ geouerj.2011.2454 (acessado em 7 março 2019).

Talaska, A. 2011. "Região e regionalização: revisão conceitual e análise do processo de reconfiguração fundiária e de alteração do uso da terra na região do COREDE Norte/RS”, Caminhos de Geografia, Vol. 12 No. 37, pp.201-215, disponível em: https://bit.ly/2tWqdoD (acessado em 7 março 2019)

Tsing, A. L. 2011. Friction: An ethnography of global connection. New Jersey: Princeton University Press.

\section{Notas}

1 Para fundamentar a discussão proposta neste artigo, a expressão patrimônio cultural faz referência aos bens tangíveis imóveis.

2 O espaço natural é o espaço resultante de processos naturais e espontâneos do meio ambiente, sendo concebido como o espaço no qual o homem não exerceu influência e não realizou transformações em suas paisagens (Talaska, 2011).

3 [Organização das Nações Unidas para a Educação, a Ciência e a Cultura (2018), "Patrimônio | Cultural Imaterial", avaiable at http://www.unesco.org/new/en/unesco/resources/ (acessado em 17 março 2019)]

4 São aquelas instalações que existem para atender a outras necessidades da comunidade, mas fundamentais para o turista (ver Barreto, 2000).

5 A essa situação é atribuída a expressão “cidade partida” (Paes, 2015). 